\title{
Disseminated Tuberculosis Related to Child Acute Cytomegalovirus Infection
}

\author{
NICOLETA NEGRUT ${ }^{1}$, SIMONA BUNGAU ${ }^{1}$, PAULA MARIAN ${ }^{1}$, LAURA ENDRES ${ }^{*}$, \\ MARIUS RUS ${ }^{1 *}$, CRISTIANA BUSTEA ${ }^{1}$, CRISTINA BARDACA (URDUCEA) ${ }^{2}$, \\ CRISTIAN SAVA ${ }^{1}$ \\ ${ }^{1}$ University of Oradea, Faculty of Medicine and Pharmacy, 1 Uiversitatii Str., 410087, Oradea, Romania \\ ${ }^{2}$ University Politehnica of Bucharest, Applied Chemistry and Materials Science Faculty, 1-7 Polizu Str.,011061, Bucharest, \\ Romania
}

Abstract: The spreading of Mycobacterium tuberculosis (MT) through lymphohematogenous pathways with multi-organ damage is disseminated tuberculosis (DT). The case of a child presenting disseminated tuberculosis and who had an acute cytomegalovirus (CMV) infection at the onset of the disease is described in this study. Patient aged 2 presented to Municipal Clinical Hospital of Oradea, Oradea, Romania area with high fever, generalized lymphadenopathy, multiple abscesses of the skin, poor growth, having a background with numerous hospitalizations for respiratory infections in the paediatric department. Chest and head radiography and computed tomography of the same areas show bilateral pleural effusion and osteolytic lesions. The presence of MT was determined from cultures of gastric aspirate and skin lesions. Serology for CMV-specific IgG and IgM antibodies was positive. The treatment of the patient was recommended following the National Tuberculosis Protocol precisely. The patient's response to treatment was slow. In order to diagnose DT in children (where this disease is severe and rare), a multidisciplinary approach combined with complex and sometimes invasive paraclinical investigations is required.

Keywords: tuberculosis, cytomegalovirus, infection

\section{Introduction}

Tuberculosis (TB) is a contagious chronic infection, caused by Mycobacterium tuberculosis (MT), which usually affects the lungs; it is spread worldwide, considered to be one of the top ten causes of death. Moreover, it can affect both adults and children, being transmitted from one person to another through respiratory route.

In most cases MT does not become active thus not generating an infection. Extreme ages or deficiencies in cell-mediated immunity (i.e., Human immunodeficiency virus infection (HIV), Cytomegalovirus infection (CMV), malnutrition, primary immunodeficiency disorders, steroid therapy, chemotherapy) are risk factors for developing TB [1,2]. The symptoms are nonspecific and difficult to differentiate from that of nontuberculous respiratory infections. Clinical features in case of pulmonary TB include fatigue, fever, night sweats, anorexia with weight loss, cough, chest pain, and hemoptysis. Evolution is progressive, clinical features last more than 3-4 weeks and do not respond to nonspecific medication.

Disseminated tuberculosis (DT) is a rare form of the disease, it is spread on lymphohematogenous pathways, and may invade all the organs, like the bone marrow, liver, lymph nodes, skin, brain, spine, eyes, or two or more non-contiguous sites, or military tuberculosis $[3,4]$. In these cases, the clinical image shows signs and symptoms specific to the affected organ. These can be headache associated with mental status changes and low-grade fever (in case of meningeal localization); back pain and signs of arthritis (for skeletal TB); dysuria, pain in flank or scrotal area, frequent urination (in case of genitourinary TB); gastrointestinal

*email:laura_endres@yahoo.com;rusmariusr@yahoo.com 
mucosa ulceration, abdominal pain, diarrheal (gastrointestinal TB); lymphadenopathy (lymph nodes localization); cutaneous lesions (skin localization). DT can imitate a large number of illnesses, does not respond to nonspecific therapy, and requires a high suspicion index. The disease can be fatal, even in case of a properly managed treatment.

Diagnosis of TB requires special tests such as Xpert MTB/RIF assay (rapid molecular tests), sputum smear microscopy, culture-based methods and MT drug-susceptibility testing.

The treatment of the disease requires concomitant administration of more antitubercular agents for a prolonged period. The administration should be directly observed, the doses must be often adjusted according to the changes in the child's body weight. The polymorphic clinical picture, often nonspecific, associated with a long period of time necessary for diagnosis confirmation and correlated with slow evolution under the treatment, makes DT a potentially life-threatening disease. If all these are present in the case of immunocompromised patients, the disease can be fatal, even in case of a properly managed treatment.

The purpose of this study is to present a rare but severe form of the disease in children, whose diagnosis required interdisciplinary approaches, as well as paraclinical investigations not frequently used in the pathology of the child.

\section{Materials and methods}

A 2-year-old female patient, prematurely born, properly vaccinated with BCG vaccine, with multiple hospitalizations in various medical services for successive acute lower respiratory infections, is being admitted in the paediatric service of Municipal Clinical Hospital of Oradea, Romania, in September 2017 for multiple skin abscesses (Figure 1), generalized lymphadenopathy, high fever, failure to develop (body mass index for age lower than $5^{\text {th }}$ percentile).

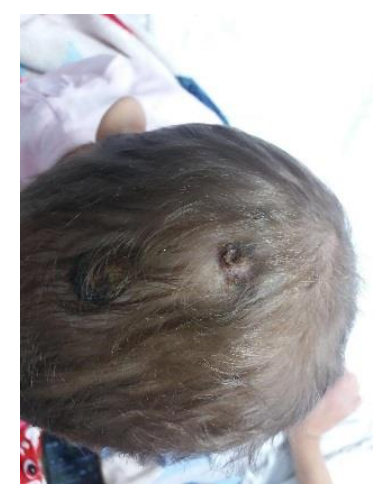

Figure 1. Skin abscess at the head level

\section{Results and discussions}

The results obtained during laboratory investigations are presented in Table 1.

Table 1. Laboratory investigations

\begin{tabular}{|c|c|c|}
\hline Investigated parameters & Results & Reference range \\
\hline White blood cells $($ cells/ $\mu \mathrm{L})$ & $29.3 \times 10^{3}$ & $7.0-13.0 \times 10^{3}$ \\
\hline Red blood cells (cells/ $\mu \mathrm{L})$ & $3.03 \times 10^{6}$ & $3.83-4.67 \times 10^{6}$ \\
\hline Haemoglobin $(\mathrm{g} / \mathrm{dL})$ & 4.7 & $10.8-12.6$ \\
\hline Mean corpuscular volume $(\mathrm{MCV})(\mathrm{fL})$ & 49.6 & $76.6-83.2$ \\
\hline Mean corpuscular haemoglobin $(\mathrm{MCH})(\mathrm{pg})$ & 11.5 & $26.5-29.3$ \\
\hline $\begin{array}{c}\text { Mean corpuscular haemoglobin } \\
\text { concentration }(\mathrm{MCHC})(\mathrm{g} / \mathrm{dL})\end{array}$ & 23.2 & $34.1-35.6$ \\
\hline Platelets (cells/ $\mu \mathrm{L})$ & $606 \times 10^{3}$ & $211-408 \times 10^{3}$ \\
\hline C-reactive protein $(\mathrm{mg} / \mathrm{L})$ & 232 & $0-5$ \\
\hline Serum iron level $(\mathrm{ng} / \mathrm{dL})$ & 13.9 & $40-100$ \\
\hline Serum ferritin levels $(\mathrm{ng} / \mathrm{mL})$ & 36.5 & $9.8-73$ \\
\hline
\end{tabular}


The culture from the abscess was repeatedly negative (for non-specific agents). Serological markers for $\mathrm{CMV}$ were positive for specific $\mathrm{M}$ and $\mathrm{G}$ immunoglobulins ( $\mathrm{Ig}$ ), but negative for Toxoplasma gondii. The HIV antibodies were negative.

The patient was treated with transfusion of packed red blood cells, an association of antibiotics and antifungal medication. Antiviral treatment was not initiated due to the small age and the presence of severe anemia. Under treatment with broad-spectrum antibiotics (Teicoplanin, Meropenem, Amikacin, and after Vancomycin with Linezolid) evolution was unfavourable, which is why chest computed tomography scan (CT) was performed. CT describes osteolytic lesions disseminated to the chest bone (Figure 2).

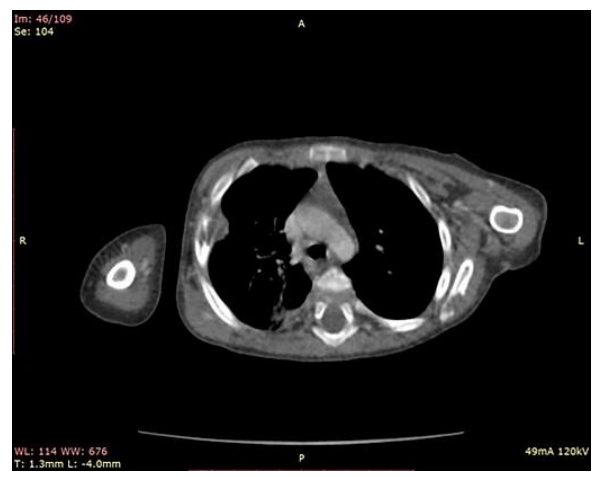

Figure 2. Osteolytic lesions

(Chest CT - 22.11.2017)

The administered treatment was Clindamycin, Imipenem, and Piperacillin/Tazobactam. Evolution is dragged with the persistence of suppurations and osteolytic lesions. The tuberculosis aetiology was confirmed by Ziehl-Neelsen stain of skin abscess purulent fluid, positive culture of gastric aspirates and skin abscess purulent fluid on Lowenstein-Jensen medium, adenosine deaminase (ADA) increased 38U/1. Also, tuberculin intradermal reaction (IDR) at 5 UI purified protein derivative (PPD) was positive. Head CT (Figure 3), chest CT (Figure 4), magnetic resonance imaging (MRI) of the head (Figure 5); chest CT presented also bilateral pleural effusion (Figure 6). The skeletal radiographs described osteolytic lesions (Figure 7).

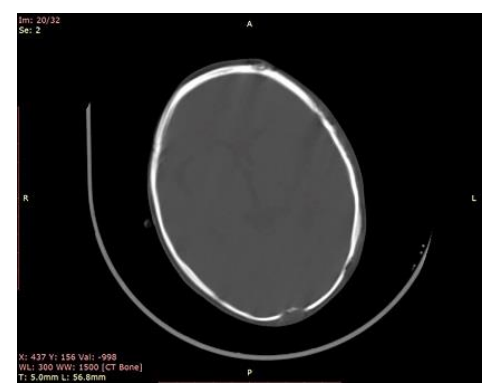

Figure 3. Osteolytic lesions (Head CT - 12.01.2018)

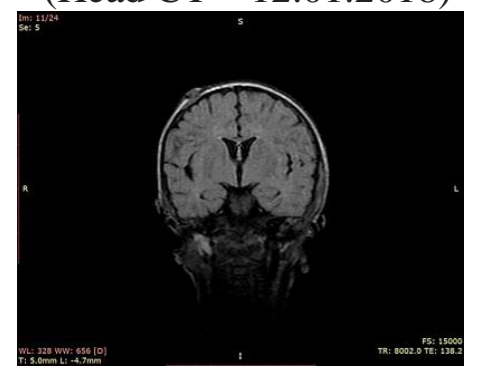

Figure 5. Osteolytic lesions (MRI of the head-02.02.2018)

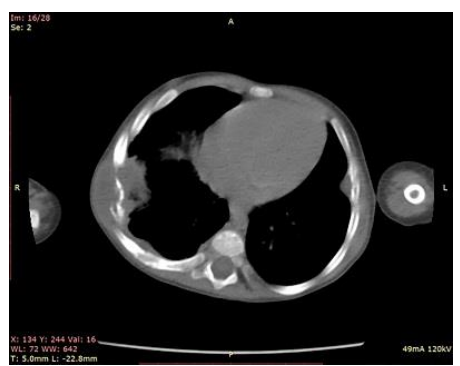

Figure 4. Osteolytic lesions (Chest CT - 12.01.2018)

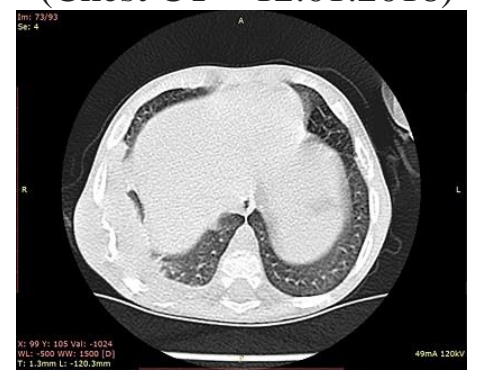

Figure 6. Pleural effusion (Chest CT - 12.01.2018) 


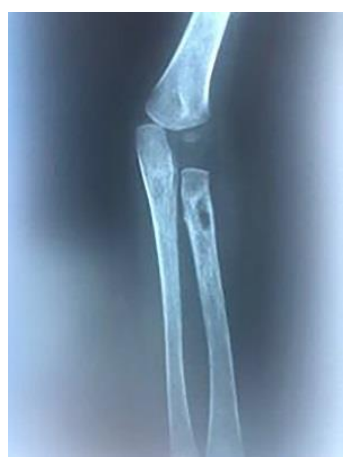

\author{
Figure 7. Osteolytic \\ lesions (Skeletal \\ radiographs $-03.02 .2018)$
}

MT drug-susceptibility testing before the treatment revealed Isoniazid and Rifampin sensitivity. Flow cytometry immunophenotyping for $\mathrm{T} \mathrm{CD}_{3}, \mathrm{~T} \mathrm{CD}_{4}, \mathrm{~T} \mathrm{CD}_{8}$, natural killer $(\mathrm{NK}) \mathrm{T}$, and $\mathrm{B}$ cells were normal. The morphological aspect at histopathological examination described from cervical lymph node and skin biopsy was compatible with a disseminated granulomatous inflammatory lesion compatible with a TB (Figure 8, 9, and 10).

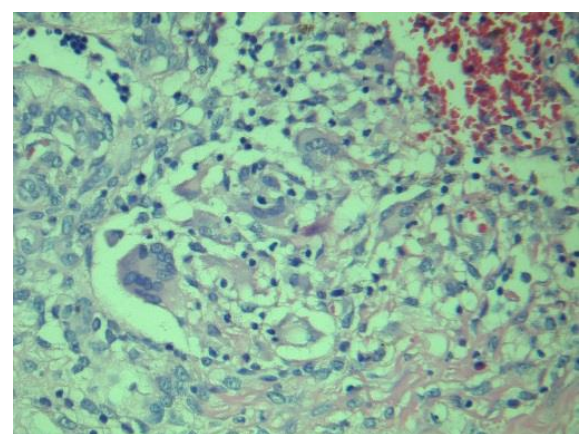

Figure 8. Small dermal granuloma with giant cells without central necrosis (Skin biopsy - 23.02.2018)

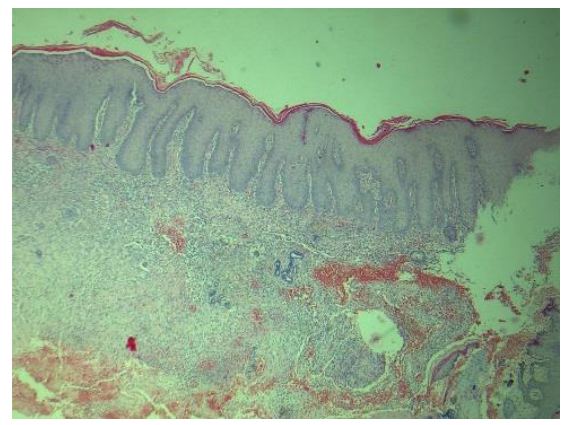

Figure 9. Epidermal hyperplasia with superficial granulomatous dermatitis (Skin biopsy - 23.02.2018)

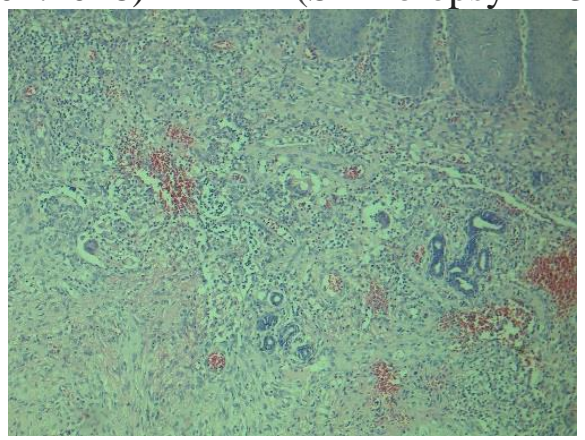

Figure 10. Dermal micro-haemorrhage and dermal granulomas (Skin biopsy - 23.02.2018)

The case has been interpreted as disseminated tuberculosis, acute CMV infection, severe iron deficiency anemia, and failure to thrive. From epidemiological point of view, the child was in contact with a neighbour diagnosed two months later with TB. The child's mother was not diagnosed with TB until now. The patient followed a treatment according to the National Tuberculosis Protocol with 3months regimen of daily administration of Isoniazid $10 \mathrm{mg} / \mathrm{kg}$ PO daily, Rifampin $15 \mathrm{mg} / \mathrm{kg}$ PO qDaily, Pyrazinamide $35 \mathrm{mg} / \mathrm{kg}$ PO qDaily, Ethambutol $20 \mathrm{mg} / \mathrm{kg}$ PO qDaily associated with Amikacin 15 $\mathrm{mg} / \mathrm{kg}$ IM (two months), then - Meropenem $40 \mathrm{mg} / \mathrm{kg}$ IV q8h (one month). After three months the treatment was continued with Isoniazid $10 \mathrm{mg} / \mathrm{kg}$ PO, and Rifampin $15 \mathrm{mg} / \mathrm{kg}$ PO, both drugs three times a week.

After two months, the evolution with the appearance of a new skin abscess, CT scanning of the same aspect, weight stagnation, persistence of inflammatory syndrome and leukocytosis determined a reserved 
prognosis of the case, which is why the case was transferred to the higher regional centre. Subsequent medical evaluation decided the association of corticosteroids in doses adjusted according to body weight, for a period of eight weeks and to maintain the association between Isoniazid and Rifampin. The patient's evolution was slowly favourable, with the resumption of appetite, weight gain, absence of other new skin lesions, normalization of the complete blood count and absence of the inflammatory syndrome.

The patient presented a recurrence of leukocytosis at $22.3 \times 10^{3}$ cells $/ \mu \mathrm{L}$ (reference range: $7.0-13.0$ $\mathrm{x} 10^{3} \mathrm{cells} / \mu \mathrm{L}$ ) and inflammatory syndrome with C-reactive protein $42 \mathrm{mg} / \mathrm{L}$ (reference range: 0-5 $\mathrm{mg} / \mathrm{L}$ ) at the evaluation at two months after cessation of corticosteroids. This is why corticosteroid therapy was reintroduced for another six weeks treatment. Laboratory parameters at the end of cortisone treatment returned to normal values. Treatment with Isoniazid, and Rifampin was continued for nine months, without interruption. The patient underwent continuous treatment for twelve months. Chest CT performed after one year of treatment showed no obvious new lesions. At this moment, the child is under clinical monitorization at three months.

Children younger than 4 , without family contact, are difficult to diagnose with TB due to non-specific respiratory signs, and variable radiological aspects [5]. Young children have a high risk of developing severe or disseminated forms of tuberculosis because the disease can mimic acute respiratory infections, very common at this age, with the delay in diagnosis [6,7]. In our case, the delay was due to the late demonstration of the contact with the adult positive for MT and the patient's personal history which presented a large number of acute respiratory tract infections. The diagnosis required complex, repeated and invasive paraclinical investigations (CT, MRI, biopsies) all these being difficult to make in case of a 2 years old child.

TB primarily affects the lungs, being usually spread from an adult to a child, in case of children younger than ten, due to low MT concentration in their secretions. Extrapulmonary TB is not transmitted [8]. Our case received the disease from her neighbour, but the relationship between the two cases was revealed very late, due to the fact that the adult has presented himself late in a medical service.

In patients younger than 4 , TB progression requires the association of risk factors, primary or secondary deficiency of cell-mediated immunity (chronic granulomatous disease, HIV co-infection, herpes viruses, steroid therapy, chemotherapy, malnutrition, cancer, zinc deficiency) $[1,2,9,10]$. Macrophages, dendritic cells, neutrophils and NK are major types of immune cells that protect the host against MT infection. In our case we have not yet been able to demonstrate primary deficits of cellmediated immunity (flow cytometry immunophenotyping with normal values). Associated severe malnutrition (failure to thrive) with acute infection with CMV in recent history (serum anti-CMV IgM antibody positive proved acute infection in the last 3-6 months) and severe iron deficiency anemia, constituted the risk factors that could cause the infection with MT in a vaccinated child, as well as its severe evolution with dissemination. Many enzymes with antibacterial action (e.g., myeloperoxidase, NADPH oxidase neutrophil, lactoferrin, lipocalin-2) contain iron or their activity is modulated by ironcontaining cofactors. Iron deficiency reduces its activity, compromising the antibacterial defence capability of the host $[11,12]$. Iron deficiency anemia, secondary to the failure to thrive, can thus be a risk factor for developing a bacterial infection. Failure to thrive is recognized as being associated with recurrent bacterial and viral infections, as well as severe immune deficiency. CMV infects mononuclear cells and lymphocytes by altering the cell mediated immune response, including natural NK cells activity. This makes the presence of CMV infection a risk factor for TB [13,14]. The combination of three immunosuppressive diseases caused the dissemination and the severity of MT infection.

Lack of response to the treatment can be due to the presence of bacterial resistance, lack of compliance to treatment, decreased absorption of a medication administered correctly. In this case, multi-drug resistant (MDR) bacteria could not be detected and the therapy was directly observed. We suspect that the presence of intestinal mucosal atrophy due to severe malnutrition can be responsible for low absorption in case of antitubercular agents with oral administration. CMV infection can alter the host's gut microbiota, already modified after many antibiotic regimens in the history of the patient [1518]. On the other hand, gut microbiota can have effects on the efficacy and toxicity of medication [19- 
21]. The requirements of laborious investigations to monitor plasma drugs concentration, correlated with the reserved prognosis of the case, determined the decision to transfer the patient to the higher regional centre.

Although corticosteroid therapy is indicated in DT [22], the association with acute CMV infection has delayed the initiation of adjuvant therapy in order not to produce a negative effect on immune system activity. Moreover, the positive effect of this therapy is not yet fully elucidated and there is little evidence to support its use [22].

The favourable, slow, undulating evolution of the case under treatment is secondary to the presence of a deficient immune system associated with CMV and MT co-infection. The possibility of tuberculosis reactivation persists in the future, which is why the patient should be closely monitored over a long period of time.

\section{Conclusions}

DT in children is a rare and severe disease for which diagnosis requires a multidisciplinary approach associated with complex and invasive paraclinical investigations. The patient presented a rare association of diseases with a negative impact on the immune system activity, which was responsible for the emergence of a severe form of DT with an unfavourable response to a properly antitubercular therapy.

\section{References}

1.LA ROSA, C, DIAMOND, D.J., Future Virol., 7, nr. 3, 2012, p. 279.

2.DOBLER, C.C., CHEUNG, K., NGUYEN, J., MARTIN, A. Eur. Respir. J., 50, nr. 2, p. 1700157.

3.WANG, J.Y., HSUEH, P.R., WANG, S.K., JAN, I.S., LEE, L.N., LIAW, Y.S., YANG, P.C., LUH, K.T. Medicine (Baltimore), 86, nr. 1, 2007, p. 39.

4.RIBEIRO, S., TRABUlO, D., CARDOSO, C., OLIVEIRA, A., CREMERS I. GE Port J. Gastroenterol., 23, nr. 4, 2006, p. 208.

5.***, CDC. Updated guidelines for using interferon gamma release assay to detect Mycobacterium tuberculosis infection-United States, 2010. MMWR., 25, 2010, p. 1.

6.BATRA, S., AYAZ, A., MURTAZA, A., AHMAD, S., HASAN, R., PFAU, R., PLoSOne, 7, nr. 7, 2012, p. e40880.

7.ESPOSiTO, S., TAGliabUE, C., BOSIS, S. Mediterr. J. Hematol. Infect. Dis., 5, nr. 1, 2013, p. e2013064.

8.AMERICAN THORACIC SOCIETY (ATS) Diagnostic standards and classification of tuberculosis in adults and children. Am. J. Respir. Crit. Care Med., 161, 2000, p. 1376.

9.NEGRUT, N., MIRCEA, N., J. Ecotoxicol., 12, nr. B, 2013, p. 291.

10.NEGRUT, N., NEGRUT, L., BMC Infect. Dis., 13, nr. Suppl. 1, 2013 , P62.

11.KURTOGLU, E., UGUR, A., BALTACI, A.K., MOGOLKOC, R., UNDAR, L., Biol. Trace. Elem. Res. 96, nr. 1-3, 2009, p. 109.

12.GANZ, T. Int. J. Hematol., 107, nr. 1, 2018, p. 7.

13.FLETCHER, H.A., SNOWDEN, M.A., LANDRY, B., RIDA, W., SATTI, I., et al. Nat. Commun., 12, nr. 7, 2016, p. 1190.

14.LIU, C.H., LIU, H., GE, B., Cell. Mol. Immunol., 14, nr. 12, 2017, p. 963.

15.HIRAO, L.A., WEBER, M.G., MENDEZ-LAGARES, G., CHANG, W.L.W., JIANG, G., DEERE, J.D., et al. J. Virol., 2018, pii: JVI.00167-18.

16.ZAHA, D.C., BUNGAU, S., ALEYA, S., TIT, D.M., VESA, C.M., POPA, A.R., PANTIS, C., MAGHIAR, O.A., BRATU, O.G., FURAU, C., MOLERIU, R.D., PETRE, I., ALEYA, L., Sci. Total Environ., 687, 2019, p. 118. https://doi.org/10.1016/j.scitotenv.2019.06.076

17.MOISA, C., VLAD, A.M., TEUSDEA, A., CADAR, O., HOAGHIA, M.A., STAN, R.L., TAEREL, A., JURCA, C., VICAS, L.G., Farmacia, 66, nr. 6, 2018, p. 1081. 
18.SPINU, D., BRATU, O., POPESCU, R., MARCU, D., RADULESCU, A., MISCHIANU, D., Rom.J. Military Med., 118, nr. 3, 2015, p. 12.

19.WILSON, I.D., NICHOLSON, J.K., Transl. Res., 179, 2017, p. 204.

20.ABDEL-DAIM, M.M., EL-TAWIL, O.S., BUNGAU, S.G., ATANASAOV, A.G., Oxid. Med. Cell. Longev., 2019, 2019, ID 4179676. https://doi.org/10.1155/2019/4179676

21.ABDEL-DAIM, M.M., ABO-EL-SOOUD, K., ALEYA, L., BUNGAU, S.G., NAJDA, A., SALUJA R., Oxid. Med. Cell. Longev., 2018, 2018, ID 6276438. https://doi.org/10.1155/2018/6276438

22.KADHIRAVAN, T., DEEPANJALI, S., Indian J. Chest Dis. Allied Sci., 52, nr. 3, 2010, p. 153.

$\overline{\text { Manuscript received: } 24.09 .2019}$ 